EPJ Web of Conferences 110,01055 (2016)

DOI: 10.1051/epjconf/201611001055

CC Owned by the authors, published by EDP Sciences, 2016

\title{
NEW APPROACH TO STUDY THE IGNITION PROCESSES OF ORGANIC COAL- WATER FUELS IN AN OXIDIZER FLOW
}

\author{
T.R. Valiullin ${ }^{1}$, M.A. Dmitrienko ${ }^{1, a}$, P.A. Strizhak ${ }^{1}$ \\ National Research Tomsk Polytechnic University, 634050 Tomsk, Russian
}

\begin{abstract}
To converge the conditions of organic water-coal fuel composition combustion in the typical power equipment we developed a new approach and installed an experimental setup, eliminating the traditional fixing the fuel droplets on the thermocouples or rods. Specialized cone-shaped chamber was used to implement the process of lingering of organic water-coal fuel droplets. Necessary and sufficient conditions for the lingering of organic water-coal fuel droplets were established. We determined the parameters of the system (droplet size of 0.4-0.6 mm, temperatures 823-903 K and the velocity of the oxidizer flow $1.5-6 \mathrm{~m} / \mathrm{s}$ ) at which the droplets were consistently ignited in the process of lingering. Minimum temperatures and ignition delay times of organic water-coal fuel droplets based on brown coal, used motor, turbine, transformer oils, kerosene, gasoline and water were defined.
\end{abstract}

\section{Introduction}

Currently, there are several approaches [1-4] for studying the features of the initiation of the stable combustion of coal-water fuel (CWF) compositions. As the most typical one can regard the injection of CWF droplets in the combustion chamber or the modeling high-temperature channels on the junction of low-inertia thermocouple [1-3], wire [4], quartz rod [4], atomization of CWF using specialized atomizers [5], the use of simplified models of the conjugate heat transfer [6], simulation by applying specialized software packages (for example, Ansys or CWF) [7].

Unfortunately, each of these approaches has some specific restrictions. In particular, at hanging the CWF droplets [1-4] on the wires, thermocouple or rods, an element used as a carrier of the droplet in the combustion device influences quite significantly on the persistence of the ignition. Applying the models of conjugate heat transfer [6] allows us to study the features of CWF droplet ignition only on an example of single droplet or a small group of them. In the specialized software packages (for example, Ansys, Fluent, CWF) [7] a group of the droplets can be researched, but it is difficult to establish the typical stages of initialization of combustion. Therefore, one needs a new approach to study the combustion processes of CWF eliminating the dedicated limitations. It seems appropriate to create a specialized chamber for lingering of fuel droplets. At the same time from the analysis [8] from the economic and environmental points of view, it is important to develop the technologies of combustion not only CWF, but also organic coal-water fuels, that is, with the addition of a liquid fuel component. Numerous statistical data [9] have shown that the amount of such combustible components from among of used motor, transformer and turbine oils are very high. And the dynamics of their growth is considerable. At that, the problems of their effective utilization are actual.

Researches $[10,11]$ have shown that a stable ignition of group of coals can be occurred at low temperatures $(600-800 \mathrm{~K}$, that is substantially lower than assumed ones in power systems). It is interesting to analyze the possible conditions of lingering and ignition of OCWF droplets at such temperatures of oxidizer.

To solve the problems of studying the ignition of lingering droplets of organic coal-water suspensions it is ought to use specialized software packages that let to perform a continuous tracking of moving objects. Studies [12, 13] have shown that Tema Automotive can be applied as a such software application.

The purpose of this work - experimental determination of necessary and sufficient conditions of lingering and subsequent ignition of OCWF droplets.

\section{Experimental procedure}

The brown coal of grade B2 (particle size is $100 \mu \mathrm{m}$ ), used motor, turbine, transformer oils and water was used as the main components for the preparation of organic coal-water fuels. On the basis of these components we prepared four compositions of OCWF by the homogenizer MPW-324. For each composition, mixing the components was made in established ratios (Table. 1).

\footnotetext{
${ }^{a}$ Corresponding author: mad2@tpu.ru
} 


\section{EPJ Web of Conferences}

Table. 1. The ratios of the components of organic coal-water mixtures.

\begin{tabular}{|l|l|}
\hline Number of composition & The ratio of the mass concentrations of the components \\
\hline Composition № 1 & Brown coal $50 \%$, motor oil $10 \%$, water $40 \%$ \\
\hline Composition № 2 & Brown coal $40 \%$, turbine oil $10 \%$, water $50 \%$ \\
\hline Composition № 3 & Brown coal $40 \%$, transformer oil $10 \%$, water $50 \%$ \\
\hline Composition № 4 & Brown coal $40 \%$, motor oil $10 \%$, water $50 \%$ \\
\hline Composition № 5 & Brown coal $40 \%$, gasoline $10 \%$, water $50 \%$ \\
\hline Composition № 6 & Brown coal $40 \%$, kerosene $10 \%$, water $50 \%$ \\
\hline
\end{tabular}

At the first stage, the components were weighed with the analytical scales ViBRA HT 84RCE. Then, the components were added into the vessel of homogenizer (capacity 0.251 ) for mixing. The duration of the process of mixing the composition was 10 minutes.

Fig. 1 shows the scheme of experimental setup destined for the study of integral characteristics of the ignition and burning of the lingering droplets of OCWF.

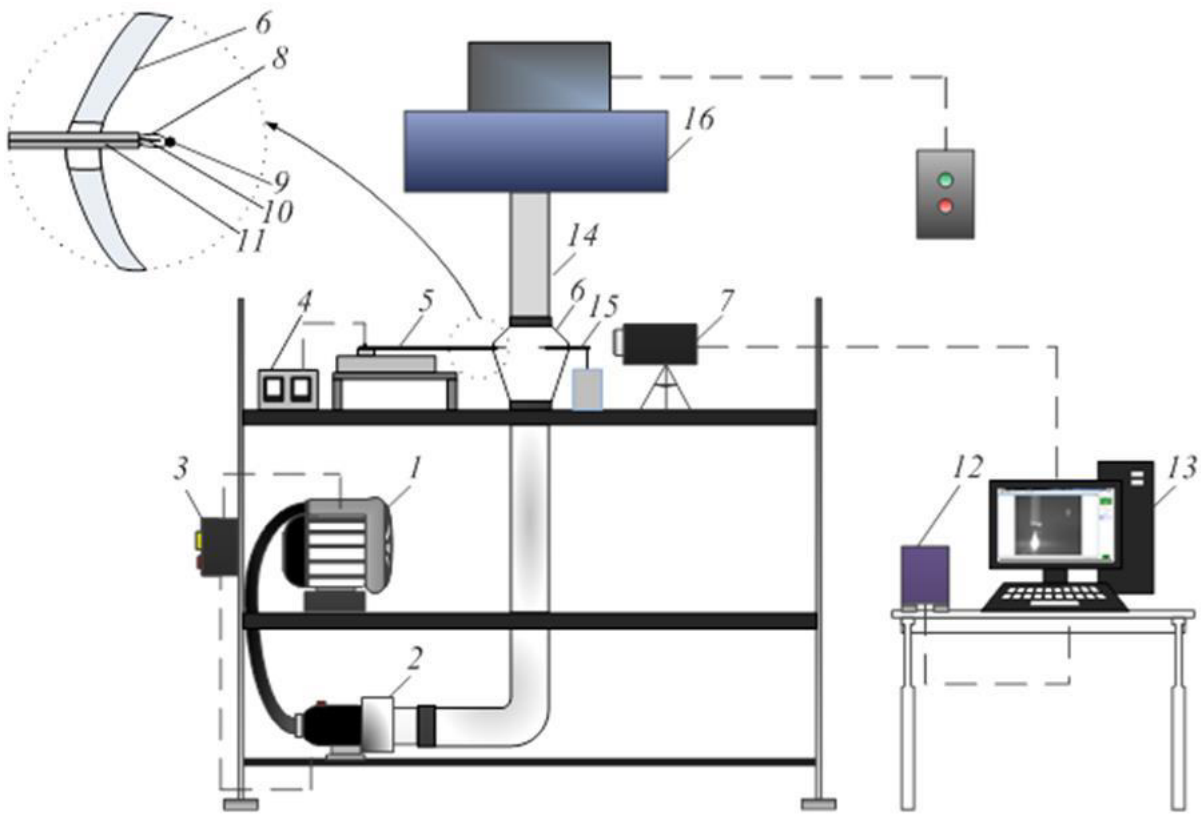

Figure 1. Scheme of experimental setup: 1 - blower; 2 - air-heater; 3 -remote control; 4 - module of power and control of the coordinate mechanism; 5 - coordinate mechanism; 6 - specialized cone-shaped quartz glass chamber; 7 - high-speed video camera; 8 -nichrome thread; 9 - the droplet of fuel composition; 10 - a cutting element (needle tip); 11 - metal hollow rods; 12 - weighing system; 13 - personal computer; 14 corrugated thermally insulated channels; 15 - digital temperature gauge (complete with a chromel-alumel thermocouple); 16 - exhaust ventilation.

Airflow of predetermined temperature $T_{g}$ was formed using a blower 1 and the air-heater 2 and directed into a cone-shaped chamber 6 made of quartz glass. The control of temperature in the chamber (on the axis of symmetry) was performed using a chromel-alumel thermocouple (temperature measurement range $273-1373 \mathrm{~K}$, systematic error of $\pm 3 \mathrm{~K}$, the rate of response not more than 3 seconds) 15 installed in the technological hole in the side surface of the chamber.

To inject and discharge the OCWF droplet in the chamber, a special construction, comprising a coordinate motorized mechanism 5 , at the tip of which we set a cutting element 10 with nichrome thread 8 , was created. The thread was held out through metal hollow rods 11 . The fuel droplet 9 generated by the dosing device was moved on the nichrome thread 8 into the chamber 6 through the technological hole in the side wall of the chamber. Cutting element 10 was used as a pusher for the discharge of the droplet from a thread after the droplet attained the axis of symmetry of the chamber 6 . The process of discharge of droplet from the thread and its size at the initial time was controlled with the use of high-speed video recording. To minimize the time of droplet injection into the chamber and its discharge, as well as preserving the integrity of the droplet when it was placed in the chamber and its discharge from the quartz thread, the optimal velocities of the coordinate mechanism movement, which amounted to $0.15-0.2 \mathrm{~m} / \mathrm{s}$, were determined. The whole time from the moment of droplet injection into the chamber up to its discharge from ceramic tip was about $1 \mathrm{~s}$ 
To ensure the droplet lingering in the chamber (after its discharge from the thread) with the help of the frequency converter, the consumption and the velocity of the oxidizer flow was varied. Chamber dimensions (internal diameter and height of the cylindrical central part $-0.264 \mathrm{~m}$ and $0.025 \mathrm{~m}$; height of input and output cone-shaped parts $-0.2 \mathrm{~m}$ and $0.05 \mathrm{~m}$, and their maximum and minimum inner diameters $-0.264 \mathrm{~m}$ and $0.086 \mathrm{~m}$ ) provided the lingering of liquid composite fuel droplets for a time until the completion of the combustion process.

By carrying out the experiments the parameters were registered: temperatures $\left(T_{\mathrm{g}}\right)$ and velocities $\left(V_{\mathrm{g}}\right)$ of oxidizer; dimensions $\left(R_{\mathrm{d}}\right)$ and the mass $\left(m_{\mathrm{d}}\right)$ of OCWF droplets; the time of droplet injection into the chamber to discharge $\left(\tau_{\mathrm{m}}\right)$; the delay time of the ignition $\left(\tau_{\mathrm{d}}\right)$ and complete combustion $\left(\tau_{\mathrm{c}}\right)$ of the droplet. Times $\tau_{\mathrm{d}}$ and $\tau_{\mathrm{c}}$ were controlled using the specialized algorithms of software Tema Automotive, allowing us to determine the characteristic color rendition - the intensity of the luminescence of the generated fuel particle sample (in the process of ignition and combustion) when continuous tracking of the control object. Thus, with using the monochrome black and white high-speed video camera and related software (Tema Automotive) in the registration area we exhibited a gradient of the color rendition that corresponds to the conditions under which a sample of fuel burnt (by the color model "RGB" 255 it was assumed that white color corresponded to the luminescence (burning) of the sample - range of "RGB" 220-255; 0 - black). In the software package Tema Automotive, this parameter was called as "Threshold". On this basis, the delay time of ignition $\left(\tau_{\mathrm{d}}\right)$ was an interval from the moment of droplet injection in the chamber up to achieving the "Threshold" level 220 , and the time of complete combustion $\left(\tau_{\mathrm{c}}\right)$ of OCWF droplet was the period from the droplet injection in the chamber up to reduce the parameter "Threshold" less than the characteristic limited level of 220.

To control the legitimacy of the use of the color model "RGB" (definition of time $\tau_{\mathrm{d}}$ and $\tau_{\mathrm{c}}$ ), additional experiments were conducted, during which a temperature $\left(T_{\mathrm{d}}\right)$ in the droplet was recorded. For this purpose, droplet of fuel composition was generated and injected into the chamber at the junction of low-inertia thermoelectric (platinum-platinum-rhodium, the measuring temperature range $273-1873 \mathrm{~K}$, the systematic error of $\pm 1 \mathrm{~K}$, the rate of response not more than 1 second, the diameter of the junction about $0.1 \mathrm{~mm}$ ) converter (instead of ceramic tip). Measured temperature in the droplet $T_{\mathrm{d}}$ provided the opportunity to monitor the implementation of common criteria of ignition and complete combustion of the fuel composition. In line with the conclusions [14, 15] as a criteria for sustainable ignition (for the considered system) we used: the simultaneous fulfillment of the inequality $T_{\mathrm{d}}>T_{\mathrm{g}}$; achieving the rate of change $T_{\mathrm{d}}$ not less $10 \mathrm{~K} / \mathrm{s}$. The combustion process was considered as a completed one when the temperature $T_{\mathrm{d}}$ was corresponded to $T_{\mathrm{g}}$.

\section{Results and discussion}

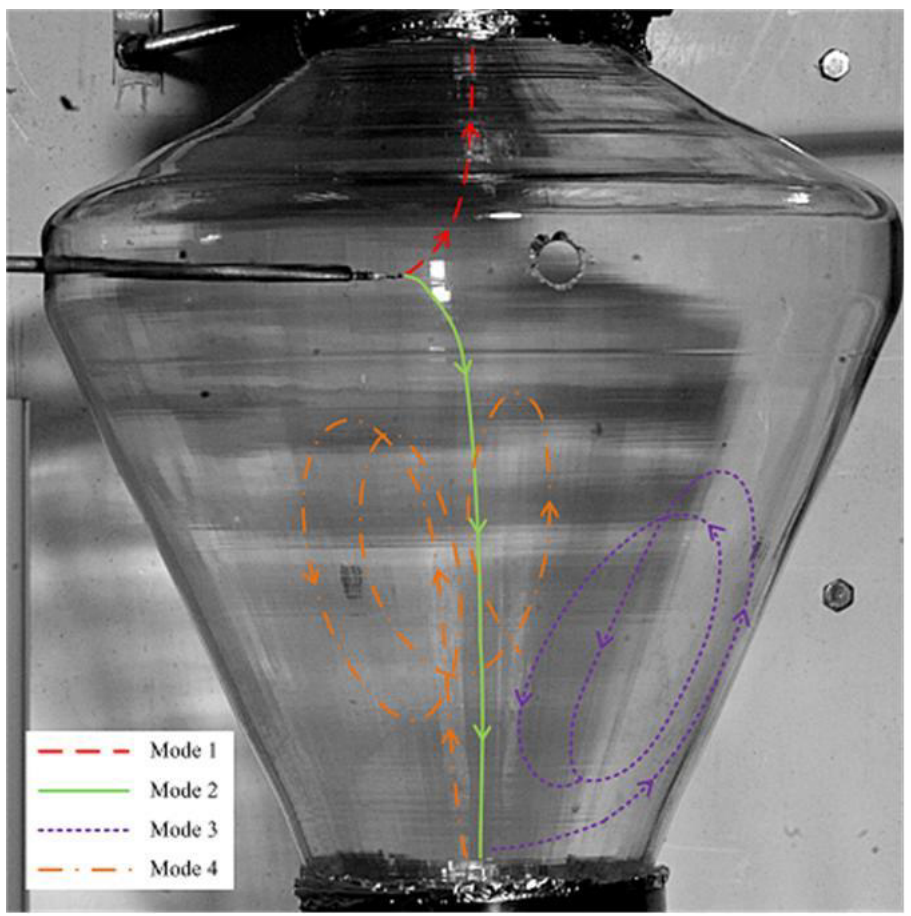

Figure 2. Videogram with modes of lingering of drop of fuel (for the conditions under which droplets are lingering and igniting).

During the experiments four regimes of organic coal-water emulsion droplet lingering in the chamber were established. At the first regime, the particle was injected into the chamber, discharged from the thread and passed to the top of the cone-shaped part of the chamber, where it stuck to the grid. At the second regime, the particle was discharged from the thread and passed to the lower cone-shaped part of the chamber, where it stuck to the grid too. The third regime was characterized by droplet lingering in the wall 


\section{EPJ Web of Conferences}

part of the chamber. Implementation of the fourth regime was considered as an ideal one. At this regime the droplet lingering was carried out in the area, located near the axis of symmetry of the chamber.

In the result of varying the temperature in the cone $(607-806 \mathrm{~K})$ and the rotation speed of pump drive $(20-50 \mathrm{~Hz})$, during the experiments, the conditions were determined. Under these conditions, the OCWF droplets did not linger and not ignited; lingered, but not ignited; lingered and ignition. Table 2 shows the conditions of lingering and the ignition for OCWF droplets based on brown coal and the used motor oil (brown coal 50\%, motor oil $10 \%$, water $40 \%$ ).

Ignition of the particle of OCWF occurred at a temperature of $823 \mathrm{~K}$ (at a temperature less than $823 \mathrm{~K}$ the particle did not ignite). When a rotation speed of pump drive was $20-30 \mathrm{~Hz}$, the air flow rate was not enough to ensure the equable particle lingering in the chamber. When the maximum rotation speed of pump drive was $50 \mathrm{~Hz}$, the air flow rate in the chamber was too high and the particle passed in a corrugated insulated channel 14. As the minimum parameters, which provided equable lingering of fuel particle and its ignition, we taken the temperature in the chamber equal to $823 \mathrm{~K}$, and the rotation speed of pump drive of $40 \mathrm{~Hz}$

Table. 2. Conditions of lingering and ignition for OCWF droplets based on brown coal and used motor oil.

\begin{tabular}{|c|c|c|c|c|c|c|c|c|}
\hline \multirow{3}{*}{$\begin{array}{c}\text { Temperature } \\
\text { of the air-heater, } \mathrm{K}\end{array}$} & \multirow{2}{*}{\multicolumn{4}{|c|}{$\begin{array}{c}\text { Temperature in the chamber, } \mathrm{K} \\
\text { Rotation speed of pump drive, } \mathrm{Hz}\end{array}$}} & \multirow{2}{*}{\multicolumn{4}{|c|}{ Pump frequency, $\mathrm{Hz}$}} \\
\hline & & & & & & & & \\
\hline & 20 & 30 & 40 & 50 & 20 & 30 & 40 & 50 \\
\hline 673 & 607 & 625.7 & 627 & 632.7 & $\begin{array}{l}\text { the particle not } \\
\text { linger, not } \\
\text { ignite }\end{array}$ & $\begin{array}{l}\text { the particle is } \\
\text { lingering, not } \\
\text { ignite }\end{array}$ & $\begin{array}{l}\text { the particle is } \\
\text { lingering, not } \\
\text { ignite }\end{array}$ & $\begin{array}{l}\text { the particle is } \\
\text { lingering, not } \\
\text { ignite }\end{array}$ \\
\hline 723 & 595 & 672 & 674.7 & 676.7 & $\begin{array}{l}\text { the particle is } \\
\text { lingering, not } \\
\text { ignite }\end{array}$ & $\begin{array}{l}\text { the particle is } \\
\text { lingering, not } \\
\text { ignite }\end{array}$ & $\begin{array}{l}\text { the particle is } \\
\text { lingering, not } \\
\text { ignite }\end{array}$ & $\begin{array}{l}\text { the particle is } \\
\text { lingering, not } \\
\text { ignite }\end{array}$ \\
\hline 773 & 667 & 712.7 & 684 & 698.7 & $\begin{array}{l}\text { the particle is } \\
\text { lingering, not } \\
\text { ignite }\end{array}$ & $\begin{array}{l}\text { the particle is } \\
\text { lingering, not } \\
\text { ignite }\end{array}$ & $\begin{array}{l}\text { the particle is } \\
\text { lingering, not } \\
\text { ignite }\end{array}$ & $\begin{array}{l}\text { the particle is } \\
\text { lingering, not } \\
\text { ignite }\end{array}$ \\
\hline 823 & 691.3 & 743.7 & 732.3 & 729 & $\begin{array}{l}\text { the particle is } \\
\text { lingering, not } \\
\text { ignite }\end{array}$ & $\begin{array}{l}\text { the particle is } \\
\text { lingering, not } \\
\text { ignite }\end{array}$ & $\begin{array}{l}\text { the particle is } \\
\text { lingering, and } \\
\text { ignite }\end{array}$ & $\begin{array}{l}\text { the particle is } \\
\text { lingering, and } \\
\text { ignite }\end{array}$ \\
\hline 873 & 713.7 & 778 & 769 & 780.7 & $\begin{array}{l}\text { the particle is } \\
\text { lingering and } \\
\text { ignite }\end{array}$ & $\begin{array}{l}\text { the particle is } \\
\text { lingering and } \\
\text { ignite }\end{array}$ & $\begin{array}{l}\text { the particle is } \\
\text { lingering and } \\
\text { ignite }\end{array}$ & $\begin{array}{l}\text { the particle is } \\
\text { lingering and } \\
\text { ignite }\end{array}$ \\
\hline 903 & & 805.7 & 782.3 & 794.7 & $\begin{array}{l}\text { the particle is } \\
\text { lingering and } \\
\text { ignite }\end{array}$ & $\begin{array}{l}\text { the particle is } \\
\text { lingering and } \\
\text { ignite }\end{array}$ & $\begin{array}{l}\text { the particle is } \\
\text { lingering and } \\
\text { ignite }\end{array}$ & $\begin{array}{l}\text { the particle is } \\
\text { lingering and } \\
\text { ignite }\end{array}$ \\
\hline
\end{tabular}



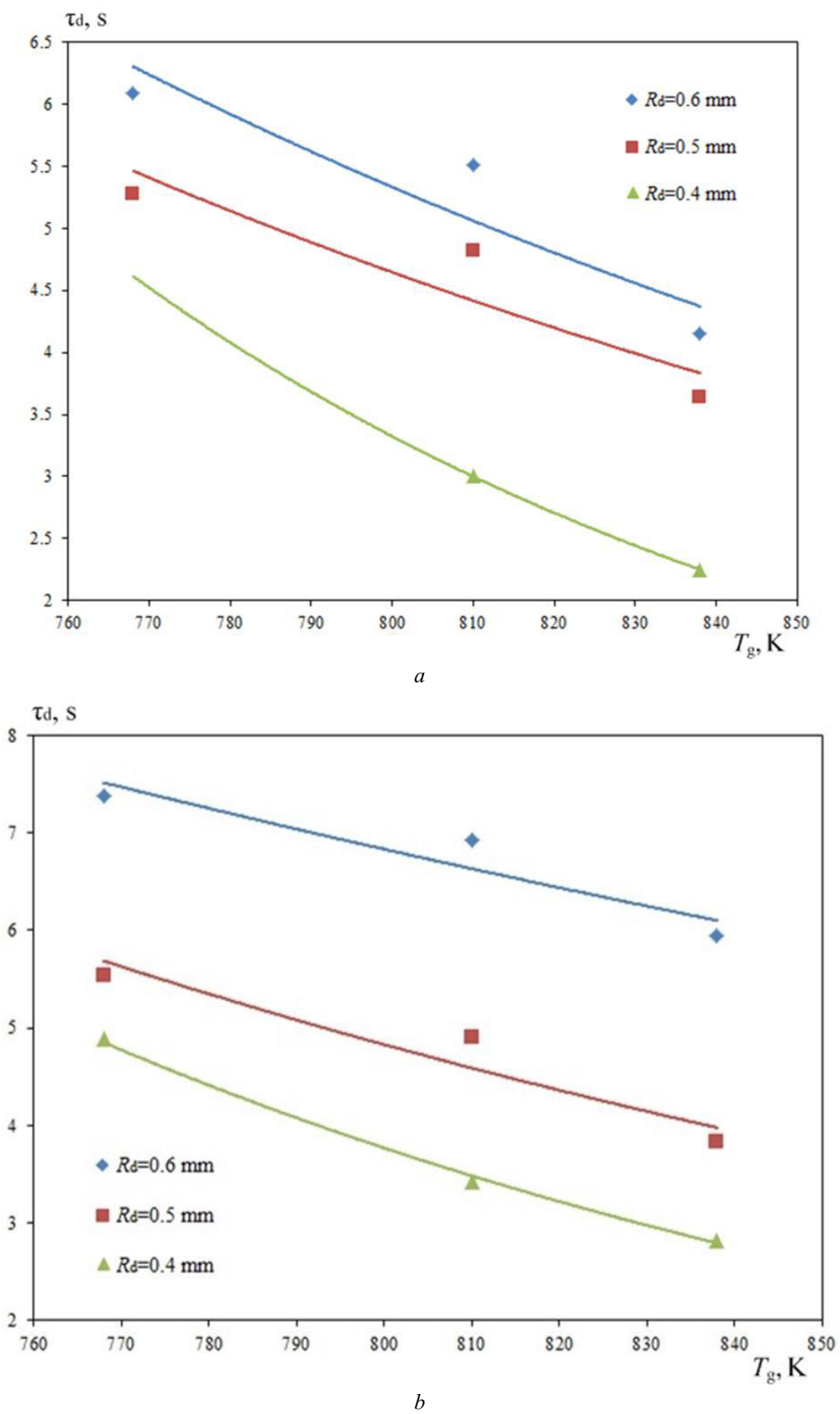


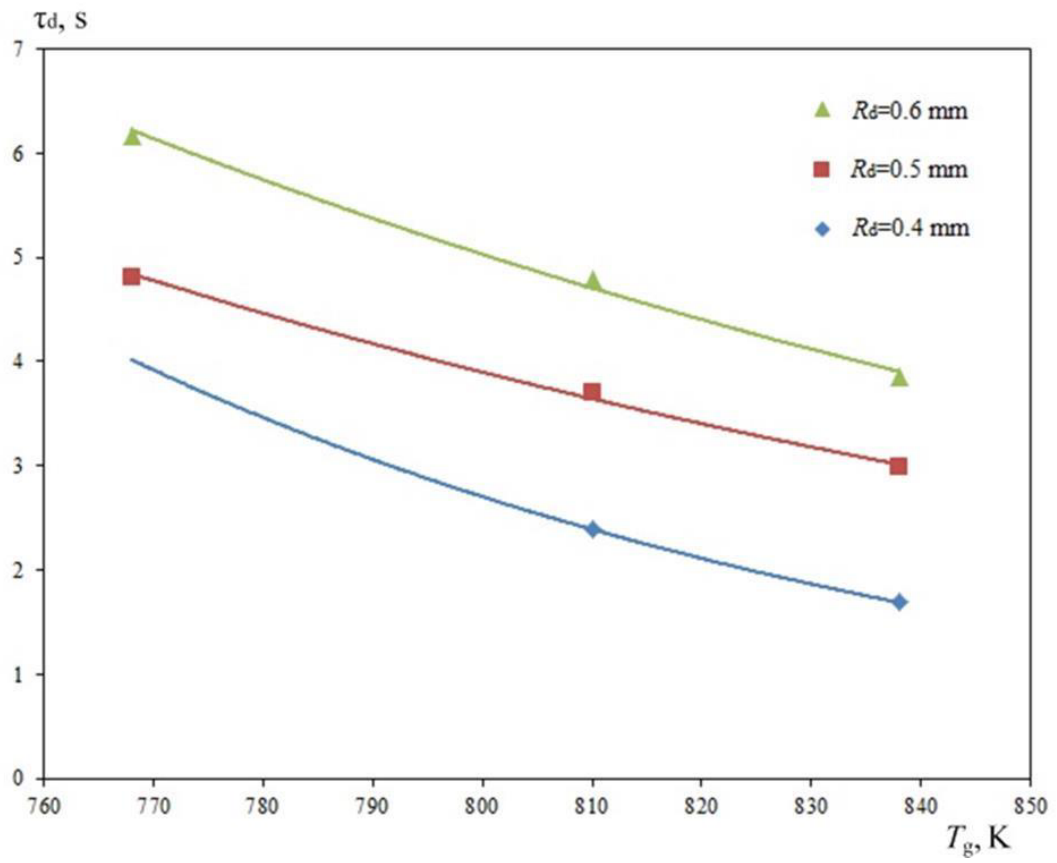

$\tau_{\mathrm{d}, \mathrm{S}}$

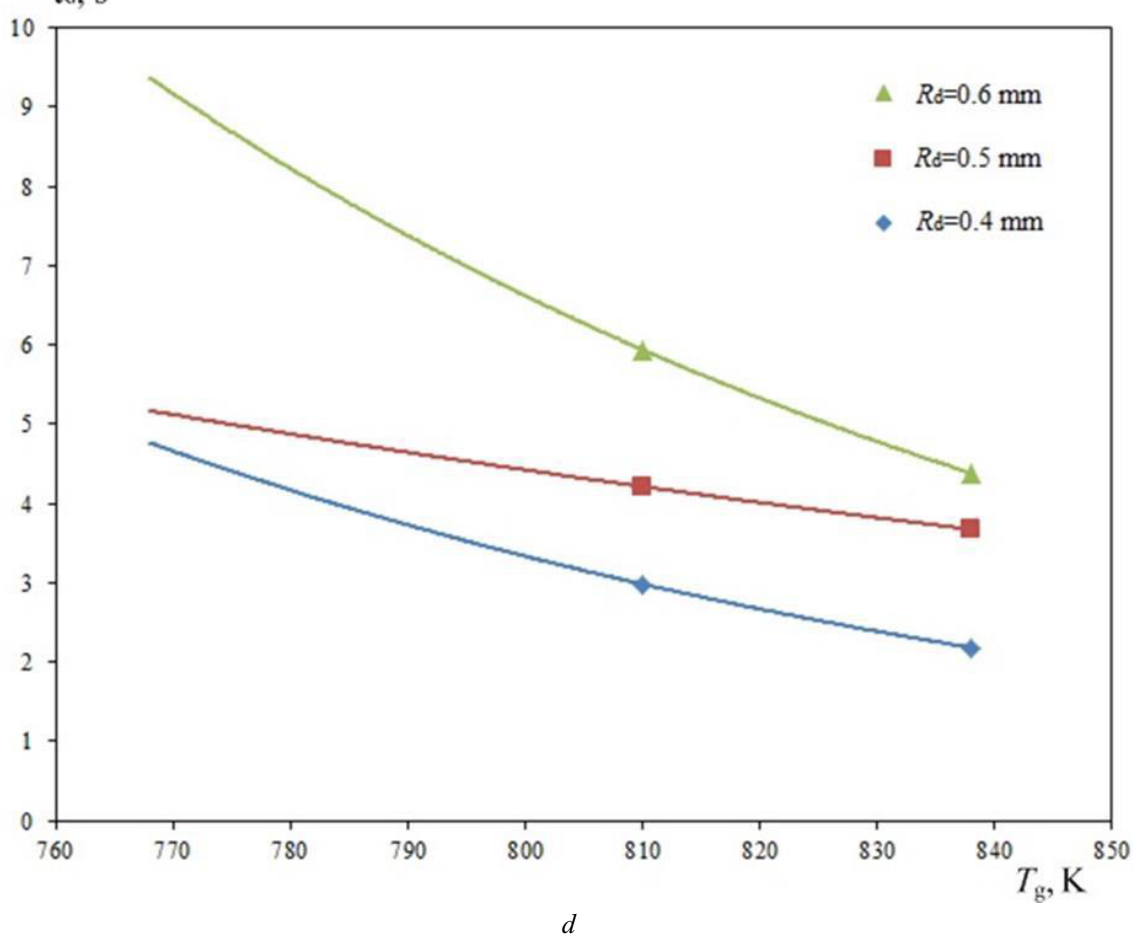

Figure 3. Delay times of ignition from the temperature of oxidizer (for the conditions under which the particles are lingering and ignite): $a-$ for OCWF droplets based on brown coal $40 \%$, turbine oil $10 \%$, water $50 \% ; b$ - for OCWF droplets based on brown coal $40 \%$, motor oil $10 \%$, water $50 \%$; $c$ - for OCWF droplets based on brown coal $40 \%$, kerosene $10 \%$, water $50 \%$; $d$ - for OCWF droplets based on brown coal $40 \%$, gasoline $10 \%$, water $50 \%$. 
The experimental dependences presented in Fig. 3 has a nonlinear character. It is seen that with increasing the oxidizer temperature $T_{\mathrm{g}}$ there is a decrease of the values of the ignition delay times $\tau_{\mathrm{d}}$. This is due to that fact that the dependencies of thermal decomposition velocities of the organic mass of coal, vaporization of liquid combustible (oil) and non-combustible (water) components, gas-phase ignition of the volatile and heterogeneous ignition of the coke residue from the temperature usually has the exponential form.

Increasing the size of organic coal-water suspension droplets $R_{\mathrm{d}}$ also leads to increase in the inertia of ignition process. This can be explained by the fact that the component characterizing the inert heating of fuel composition provides the dominant influence on the ignition delay times $\tau_{\mathrm{d}}$.

In comparing the delay times of ignition of OCWF droplets with the addition of various liquid fuel components (used motor, turbine, transformer oils, kerosene and gasoline), one can conclude that the smallest values of the ignition delay times of all the studying compounds are observed for particles on the basis of brown coal and kerosene and they were within the range of 1.7-6.2 $\mathrm{s}$. The highest values of the ignition delay times are observed for the composition based on brown coal and gasoline and they are within the range of 2.2-9.4 s.

\section{Conclusion}

The developed approach in distinction from known ones allows determining the integral characteristics of the ignition processes of the organic coal-water fuel droplets in the oxidizer flow (excluding the influence of heat sink or additional inflow from the element on which the droplet is injected in the oxidizer medium - for example, rod, wire, thermocouple and other). The experimental results and their comparison with the data of previous experiments illustrates that the delay times of ignition can be significantly lower when the droplets are lingering (similar to the combustion chambers) than the data presented in the works $[3,4]$. As a consequence, it is advisable to extend the approach on the organic coal-water fuels and coal-water fuels with prevalent component compositions.

This work supported by the Russian Science Foundation, project 15-19-10003.

\section{References}

1. Gajewski W., Kijo-Kleczkowska A., Leszczynski J., Fuel, 88 (2), 221 (2009)

2. Kijo-Kleczkowska A., Fuel, 90 (2), 865 (2011)

3. Glushkov D.O., Strizhak P.A., Vershinina K.Yu, Matec Web of Conference, 23, 01063 (2015)

4. Chebochakova D.A., Glushkov D.O., Lyakhovskaya O.E., Sukhanov S.V., Matec Web of Conference (23), 01045 (2015)

5. A.P. Burdukov, V.I. Popov, T.S. Yusupov, M.Yu. Chernetskiy, K. Hanjalić, Fuel, 122, 103 (2014)

6. Kuznetsov G.V., Salomatov V.V., Syrodoy S.V., Combustion, Explosion, and Shock Waves, 51 (4), 409 (2015)

7. Atal A., Levendis Y.A., Combust. Flame, 98 (4), 326 (1994)

8. G. S. Khodakov, E. G. Gorlov, and G. S. Golovin, Solid Fuel Chem., 40, 19 (2006)

9. A.E. Kontorovich, M.I. Epov, L.V. Eder, Russian Geology and Geophysics, 55, 534 (2014)

10. Glushkov D.O., Kuznetsov G.V., Strizhak P.A, Solid Fuel Chem., 49 (2), 73 (2015)

11. Glushkov D.O., Kuznetsov G.V., Strizhak P.A., Russian Journal of Physical Chemistry B, 9 (2), 242 (2015)

12. Glushkov D.O., Strizhak P.A., Vysokomornaya O.V., Thermal Science, 19 (1), 285 (2015)

13. Kuznetsov G.V., Piskunov M.V., Strizhak P.A., Int. J. Heat Mass Transfer, 92, 360 (2016)

14. Q. He, D. Xie, R. Xu, T. Wang, B. Hu, Fuel, 159, 40 (2015)

15. J. Zhu, G. Zhang, G. Liu, Q. Qu, Y. Li., Fuel Process. Technol., 118, 187 (2014) 